\title{
Raised Arterial Pressure and Microalbuminuria in Type 2 Diabetic Subjects with Familial Hypertension
}

\author{
Md. Anisur Rahman ${ }^{1}$ Md. Mostarshid Billah², Palash Mitra ${ }^{3}$, Md. Emtiaz Hossan ${ }^{4}$, Md. Jakir Hossain ${ }^{5}$, Wasim
} Md. Mohosin ul Haque ${ }^{6}$, Md. Abul Mansur ${ }^{7}$

\begin{abstract}
Background and Aims : Microalbuminuria is claimed to be an early marker of nephropathy in type 2 diabetes. The raised arterial pressure is an important factor in the progression of diabetic nephropathy. There is a significant correlation between blood pressure and the progression of albuminuria in both type 1 and type 2 diabetes. This study in Bangladeshi type 2 diabetic patients was to evaluate whether microalbuminuria and raised arterial pressure are influenced by familial predisposition to hypertension.
\end{abstract}

Methods : Sixty three newly diagnosed Bangladeshi type 2 diabetic patients were investigated. The diabetic subjects were divided into two groups as diabetes with family history of hypertension $(n=37)$ and diabetes without family history of hypertension ( $n=26)$. Diabetic subjects were further divided into normotensive $(n=46)$ and hypertensive $(n=$ 17); diabetic normoalbuminuric (n 44) and diabetic microalbuminuric (n 19) subgroups. Serum glucose was measured by glucose-oxidase; blood urea, serum creatinine and urinary creatinine by enzymatic-colorimetric method and urinary albumin by immunoturbidimetry method.

Results : systolic blood pressure (SBP), diastolic blood pressure (DBP) and microalbuminuria were significantly elevated in diabetic subjects with familial predisposition to hypertension when compared to diabetic subjects without

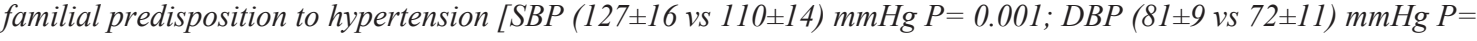
0.001; Microalbuminuria 2.23(0.28-9.43) vs 1.52(.29-3.91) $\mathrm{mg} / \mathrm{mmol} p<0.03]$. When diabetic normotensive subjects were compared with diabetic hypertensive subjects for microalbuminuria, no significant difference was found among themselves [median (range) 1.67(0.17-8.62) vs 1.70(.28-9.43) $\mathrm{mg} / \mathrm{mmol} \mathrm{p}=\mathrm{NS}$ ]. Comparison of blood pressure was found no significant difference between diabetic normoalbuminuric and diabetic microalbuminuric subjects [systolic blood pressure (117 \pm 17 vs 125 \pm 17$) \mathrm{mmHg} p=N S$; diastolic blood pressure (76 \pm 11 vs 82 110$) \mathrm{mmHg} p=N S$ ].

Conclusion : Microalbuminuria, a marker of early diabetic nephropathy and raised arterial pressure, a progression factor of nephropathy are more influenced by familial predisposition to hypertension in diabetic population irrespective of presence or absence of microalbuminuria and hypertension.

Key words : Hypertension, microalbuminuria, diabetes mellitus, familial predisposition to hypertension and diabetic nephropathy.

\section{Introduction :}

Diabetic nephropathy is characterized by persistent albuminuria, a relentless decline in glomerular filtration rate (GFR), raised arterial pressure and increased relative mortality for cardiovascular diseases. ${ }^{1}$ Diabetic nephropathy ( $\mathrm{DN}$ ) is one of those complications which has a prevalence of $7 \%$ to $21 \%$ reported in different studies conducted in $\mathrm{Asia}^{2}$. The prevalence of DN in Bangladesh is $17.9 \%$ among those who are diabetic for $>10$ years $^{3}$. It is the leading cause of End-stage Renal Disease (ESRD) requiring dialysis in developed countries ${ }^{5}$ and it is the second common cause of ESRD in Bangladesh. ${ }^{6}$ Chronic dialysis treatment obviously decreases the quality of life and creates tremendous financial responsibility for the patient and society. So, it is very much essential to detect renal involvement at an early stage and to prevent, or at least retard, the progression of renal insufficiency.

The raised blood pressure is an important factor in the progression of renal disease in diabetes, even from the initial phase of the slight elevation of the albumin excretion rate. There is a significant correlation between blood pressure and the progression of albuminuria in both type 1 and type 2 diabetes. $^{22}$
Microalbuminuria predicts the development of diabetic nephropathy and increase blood pressure contributes to the progression of nephropathy in type 1 diabetes. $^{7}$ Also in type 2 diabetes it is predictive of clinical proteinuria and increase mortality. ${ }^{8}$

Diabetic nephropathy occurs only in a subset of diabetic patients, approximately 30 to 40 percent in type 1 diabetes and 30 percent in type 2 diabetes of more than 10 years of duration. ${ }^{9,10}$ Why only one third of diabetic patients develop nephropathy can not be explained solely by differences of glycemic control. ${ }^{11}$ Hypertension in patients with type 1 diabetes develops mainly in those who are proteinuric. Those who do not develop nephropathy remain normotensive despite longer duration of diabetes and advancing age. ${ }^{30,31}$ Familial clustering of diabetic nephropathy has been reported in type 1 diabetes. ${ }^{12}$ A genetic influence of the development of nephropathy has similarly been described in Pima Indians with type 2 diabetes. ${ }^{13}$

These observations suggest that genetic factors are involved in the susceptibility to develop hypertension and diabetic nephropathy.

The aim of this study in type 2 diabetic patients with family 
history of hypertension was to evaluate the possible genetic influence of familial predisposition to hypertension on the development of raised arterial pressure and microalbuminuria in newly detected type 2 diabetic subjects irrespective of presence or absence of hypertension.

\section{Materials and Methods :}

This cross sectional study was carried out in the Department of Nephrology, Bangabandhu Sheikh Mujib Medical University (BSMMU), Dhaka in collaboration with Biomedical Research Group, Bangladesh Institute of Research \& Rehabilitation in Diabetes, Endocrine and metabolic Disorders (BIRDEM) and Analytical Division, Bangladesh Council for Scientific and Industrial Research (BCSIR), Dhaka during the period of $2004-2006$. Sixty three newly detected untreated type 2 diabetic patients (42 men and 21 women) were included in this study. Diabetic subjects were selected from Outpatient Department of BIRDEM General Hospital. They were considered diabetic according to WHO criteria. ${ }^{26}$

The diabetic subjects were studied by dividing them into several groups in the following way:

Based on family history of hypertension: a) Diabetes with family history of hypertension, FH (+)ve group. b) Diabetes without family history of hypertension, FH (-)ve group.

Based on presence or absence of hypertension: a) Diabetes with hypertension, hypertensive group.

b) Diabetes without hypertension, normotensive group.

1. Dr. Md. Anisur Rahman, MD (Nephrology), Junior Consultant, Nephrology and Dialysis, BIRDEM General Hospital, Dhaka, Bangladesh

2. Dr. Md. Mostarshid Billah, FCPS (Medicine), Junior Consultant, Nephrology and Dialysis, BIRDEM General Hospital, Dhaka, Bangladesh

3. Dr. Palash Mitra, MBBS, Assistant Registrar, Nephrology and Dialysis, BIRDEM General Hospital, Dhaka, Bangladesh

4. Dr. Md. Emtiaz Hossan, MBBS, Senior Medical Officer, Nephrology and Dialysis, BIRDEM General Hospital, Dhaka, Bangladesh

5. Dr. Md. Jakir Hossain, MBBS; Senior Medical Officer, Nephrology and Dialysis, BIRDEM General Hospital, Dhaka, Bangladesh

6. Dr.Wasim Md. Mohosin ul Haque, FCPS (Medicine), Associate Professor, Nephrology, BIRDEM General Hospital, Dhaka, Bangladesh

7. Prof. Md. Abul Mansur, Dip (Nephrology), Professor, Nephrology and Dialysis; Director, Transplant Unit, BIRDEM General Hospital, Dhaka, Bangladesh.

\section{Corresponding Author :}

Dr. Md. Anisur Rahman

Junior Consultant

Department of Nephrology and Dialysis

BIRDEM General Hospital

122 Kazi Nazrul Islam Avenue,

Shahbag, Dhaka-1000, Bangladesh

Email: anisurrahman577@yahoo.com
Based on presence or absence of microalbuminuria: a) Diabetes with microalbuminuria, microalbuminuric group. b) Diabetes without microalbuminuria, normomicroalbuminuric group.

Medical histories of the patients were taken carefully. Clinical parameters (age, sex, body mass index (BMI), blood pressure and family history of hypertension ) were recorded in a predesigned data sheet for the study. Blood pressure was measured into two consecutive office visits in a sitting position after a 5-10 min rest by sphygmomanometer. The median value of the two visit readings was used for classifying patients into two groups according to WHO criteria. A positive family history of hypertension if one or both parents had been diagnosed hypertensive or were undergoing treatment for hypertension.

Specific laboratory investigations (blood glucose fasting and 2 hours post glucose load, serum urea, serum creatinine, albumin creatinine ratio (ACR) were done in each patient. Biochemical parameters were recorded in a predesigned data for the study.

Serum glucose was measured by glucose-oxidase method. serum urea, serum creatinine, and urinary creatinine were measured by enzymatic colorimetric methods. Urinary albumin (microalbuminuria) was measured by immunoturbidimetry method.

First voided morning urine samples were collected in a clean test tube and centrifuged at a rate of $3000 \mathrm{rpm}$ for 10 minutes. $1.5 \mathrm{ml}$ of clear urine sample was transferred into amicrocentrifuge tube preserved at $-70^{\circ} \mathrm{C}$ in the freezer for analysis of urinary creatinine by alkaline picrate method and urinary albumin was estimated by immunoturbidimetry method. Another test tube containing urine was used for routine microscopic examination immediately.

Albumin creatinine ratio (ACR) was calculated from urinary creatinine and urinary albumin. Microalbuminuria (MA) was labeled in a patients when in first morning urine sample, albumin-creatinine ratio (ACR) was greater than mean $\pm 2 \mathrm{SD}$ (two standard deviation) ACR of Control subjects. An ACR of $2.0-2.5 \mathrm{mg} / \mathrm{mmol}$ to $20-35 \mathrm{mg} / \mathrm{mmol}$ corresponds to albumin excretion of $20-200 \mu \mathrm{g} / \mathrm{min}$ or $30-300 \mathrm{mg} / \mathrm{day} .{ }^{27,28,29}$ In this study control subjects mean $\pm 2 \mathrm{SD}$ of urinary albumin creatinine ratio (ACR) was $2.77 \mathrm{mg} / \mathrm{mmol}$. ACR $2.77 \mathrm{mg} / \mathrm{mmol}$ was taken as a cut-off value. Diabetic subjects with $\mathrm{ACR}<2.77 \mathrm{mg} / \mathrm{mmol}$ was designated as normoalbuminuric and subject with ACR $>2.77 \mathrm{mg} / \mathrm{mmol}$ was designated as microalbuminuric.

\section{Statistical Analysis :}

All variables are expressed as mean $\pm \mathrm{SD}$ unless otherwise stated. Albumin creatinine ratio (ACR), Serum triglyceride, C-peptide levels are expressed as median ( range ). The comparison between the groups was made either by unpaired Student's t-test or Mann-Whitney U test as required by using SPSS windows package 12.0 version and $p$ value below 0.05 was considered significant. 


\section{Results :}

Fourty six diabetic normotensive subjects were match for age, BMI, glycaemic status and renal function tests with seventeen diabetic hypertensive subjects and were studied for microalbuminuria. Comparison of microalbuminuria was found no significant difference in diabetic normotensive and diabetic hypertensive subjects [median (range) 1.67 $(0.17-8.62)$ vs $1.70(0.28-9.43) \mathrm{mg} / \mathrm{mmol}, p=\mathrm{NS}]$. (Table I)

Table I: Comparison in diabetic normotensive and diabetic hypertensive subjects.

\begin{tabular}{llll}
\hline $\begin{array}{l}\text { Diabetic } \\
\text { Features }\end{array}$ & $\begin{array}{l}\text { Diabetic } \\
\text { Normotensive } \\
(\mathrm{n}=46)\end{array}$ & $\begin{array}{l}\text { hypertensive } \\
(\mathrm{n}=17)\end{array}$ & $P$ value \\
\hline Age $($ Years $)$ & $45 \pm 4$ & $45 \pm 4$ & $\mathrm{NS}$ \\
BMI $\left(\mathrm{Kg} / \mathrm{m}^{2}\right)$ & $23.7 \pm 3.5$ & $26 \pm 3.6$ & $\mathrm{NS}$ \\
FPG $(\mathrm{mmol} / \mathrm{L})$ & $12.2 \pm 5.7$ & $9.9 \pm 2.7$ & $\mathrm{NS}$ \\
2h PG (mmol/L) & $20.2 \pm 7.7$ & $19.8 \pm 4.4$ & $\mathrm{NS}$ \\
Blood urea $(\mathrm{mg} / \mathrm{dl})$ & $27 \pm 7$ & $29 \pm 8$ & $\mathrm{NS}$ \\
S creatinine (mg/dl) & $1.25 \pm 0.16$ & $1.0 \pm 0.36$ & $\mathrm{NS}$ \\
ACR (mg/mmol) & $1.67(0.17-8.62)$ & $1.70(.28-9.43)$ & $\mathrm{NS}$
\end{tabular}

$\mathrm{NS}=$ not significant

Out of 63 diabetic subjects studied, 19 (30\%) were microalbuminuric and $44 \quad(70 \%)$ subjects were normoalbuminuric. Fourty four diabetic normoalbuminuric subjects were match with nineteen diabetic microalbuminuric subjects. Comparison of blood pressure was found no significant difference between diabetic normoalbuminuric and diabetic microalbuminuric subjects [systolic blood pressure $(117 \pm 17$ vs $125 \pm 17) \mathrm{mmHg} p=\mathrm{NS}$; diastolic blood pressure (76 \pm 11 vs $82 \pm 10) \mathrm{mmHg} p=\mathrm{NS}]$. (Table II)

Table II: Comparison between diabetic normoalbuminuric and diabetic microalbuminuric subjects.

\begin{tabular}{llll}
\hline Features & $\begin{array}{l}\text { Diabetic } \\
\text { normoalbuminuric } \\
(\mathrm{n}=44)\end{array}$ & $\begin{array}{l}\text { Diabetic } \\
\text { microalbuminuric } \\
(\mathrm{n}=19)\end{array}$ & P value \\
\hline Age (Years) & $45 \pm 4$ & $46 \pm 4$ & $\mathrm{NS}$ \\
BMI (Kg/m2) & $24.5 \pm 3.6$ & $24.5 \pm 2.9$ & $\mathrm{NS}$ \\
Systolic BP (mmHg) & $117 \pm 17$ & $125 \pm 17$ & $\mathrm{NS}$ \\
Diastolic BP (mmHg) & $76 \pm 11$ & $82 \pm 10$ & $\mathrm{NS}$ \\
FPG (mmol/L) & $11.4 \pm 3.9$ & $13.6 \pm 7.0$ & $\mathrm{NS}$ \\
2h PG (mmol/L) & $20.3 \pm 5.2$ & $23.0 \pm 7.5$ & $\mathrm{NS}$ \\
Blood urea (mg/dl) & $27 \pm 7$ & $27 \pm 8$ & $\mathrm{NS}$ \\
S creatinine (mg/dl) & $1.25 \pm 0.26$ & $1.23 \pm 0.14$ & $\mathrm{NS}$ \\
\hline
\end{tabular}

$\mathrm{NS}=$ not significant
Thirty seven diabetic subjects with family history of hypertension $\mathrm{FH}(+)$ ve group were matched with twenty six diabetic subjects without family history of hypertension $\mathrm{FH}$ (-)ve group and were studied for systolic blood pressure, diastolic blood pressure and microalbuminuria. The systolic blood pressure, diastolic blood pressure and microalbuminuria were significantly higher in $\mathrm{FH} \mathrm{(+)ve}$ group than FH (-)ve group. (Table III)

Table III: Comparison in diabetic subjects with family history of hypertension FH (+)ve group and diabetic subjects without family history of hypertension FH (-)ve group.

\begin{tabular}{llll}
\hline Features & FH $(+)$ ve $(\mathrm{n}=37)$ & FH $(-)$ ve $(\mathrm{n}=26)$ & P value \\
\hline Age (Years) & $45 \pm 4$ & $45 \pm 4$ & $\mathrm{NS}$ \\
BMI $(\mathrm{Kg} / \mathrm{m} 2)$ & $24.8 \pm 3.2$ & $24.1 \pm 3.7$ & $\mathrm{NS}$ \\
Systolic BP $(\mathrm{mmHg})$ & $127 \pm 16$ & $110 \pm 14$ & 0.001 \\
Diastolic BP (mmHg) & $81 \pm 9$ & $72 \pm 11$ & 0.001 \\
FPG (mmol/L) & $11.3 \pm 4.2$ & $13.1 \pm 5.9$ & $\mathrm{NS}$ \\
2h PG (mmol/L) & $20.7 \pm 5.7$ & $21.1 \pm 6.5$ & $\mathrm{NS}$ \\
Blood urea (mg/dl) & $27 \pm 7$ & $27 \pm 8$ & $\mathrm{NS}$ \\
S creatinine (mg/dl) & $1.20 \pm 0.20$ & $1.20 \pm 0.19$ & $\mathrm{NS}$ \\
ACR (mg/mmol) & $2.23(0.28-9.43)$ & $1.52(.29-3.91)$ & 0.03 \\
\hline
\end{tabular}

\section{Discussion :}

In this study population, the prevalence of hypertension is $40 \%$ in diabetics with family history of hypertension and $7.7 \%$ in diabetics without family history of hypertension. This finding is consistent with other studies in the similar populalation. ${ }^{14,32}$

To see the relation of hypertension with microalbuminuria, the diabetic hypertensive subjects were matched for age, BMI, blood glucose and renal function tests with Diabetic normotensive subjects studied for albumin creatinine ratio (ACR) or microalbuminuria. No significant difference in microalbuminuria was found between diabetic hypertensive and diabetic normotensive subjects. This result was similar with the other study in the Bangladeshi population. ${ }^{14}$

In this study population, the prevalence of microalbuminuria is $30 \%$. This finding is consistent with other studies in the Bangladeshi population. The incidence of microalbuminuria was $37 \%$ in another study with newly detected, untreated type 2 diabetic subjects. ${ }^{14}$ Three previous studies on young onset (under 30 years) type 2 diabetic subjects of Bangladeshi population also showed similar results. ${ }^{15,16,17}$ When diabetic microalbuminuric subjects were matched for age, BMI, blood glucose, lipid profile and renal function tests with diabetic normoalbuminuric subjects and studied for blood pressure . No significant difference in blood pressure was found between diabetic normoalbuminuric and diabetic microalbuminuric subjects. Hada and Iqbal also found 
similar results in type 2 diabetic subjects in the similar population. ${ }^{17,14}$ Contrary to this, increased blood pressure has been reported in type 1 diabetic patients with microalbuminuria. ${ }^{18,19}$ But there is some controversy as to whether the elevated arterial pressure precedes the development of microalbuminuria in type 1 diabetes or it occurs after its development. ${ }^{20}$ Microalbuminuria is related with blood pressure and known duration of diabetes. ${ }^{21}$ Systolic blood pressure has been found to be a determinant of microalbuminuria in type 2 diabetes. ${ }^{21}$ Nevertheless, from the earliest phase of microalbuminuria, blood pressure tends to increase by an average of 3 to $4 \mathrm{mmHg}$ per year compared with $1 \mathrm{mmHg}$ per year in long term normoalbuminuria in type 1 diabetic patients and healthy controls. ${ }^{22}$ But the absolute level of blood pressure in patients with microalbuminuria often within the conventional normotension. ${ }^{23}$

To observe the possible genetic influence of family history of hypertension on the raised arterial pressure and albumin creatinine ratio (ACR) or microalbuminuria; diabetic subjects with family history of hypertension ( $\mathrm{FH}+$ ve group) was matched for age, BMI, glycaemic status and renal function tests with diabetic subjects without family history of hypertension ( FH - ve group) and were studied for systolic blood pressure, diastolic blood pressure and microalbuminuria. The systolic blood pressure, diastolic blood pressure and microalbuminuria were significantly higher in FH (+)ve group than FH (-)ve group. This result is supported by many of the literatures that the familial predisposition to hypertension contributing to the susceptibility to diabetic nephropathy and raised arterial pressure. ${ }^{24,11}$ The association of microalbuminuria and raised arterial pressure with family history of hypertension raise the possibility that the genetics of essential hypertension and diabetic nephropathy may partially overlap. Thus any candidate gene proposed for essential hypertension can also be considered as a susceptibility gene for diabetic nephropathy. ${ }^{25}$

Therefore familial predisposition to hypertension can identify a subgroup of type 2 diabetic subjects who are prone to develop microalbuminuria and raised arterial pressure in diabetic population irrespective of presence or absence of hypertension and diabetic nephropathy.

\section{Refference :}

1. Parving HH, Tarnow L, Rossing P. Genetics of diabetic nephropathy. J Am Soc Nephrol 1996; 7:2509-27.

2. Amos AF, Mc Carty DJ, Zimmet P. Prevalence studies of diabetic complications. Diabetic Med 1997; 14: S7-S85.

3. Kibriya $\mathrm{MC}$ and Mahtab $\mathrm{H}$. Long-term microangiopathic complications in type 2 diabetics. The Dib Care - Asia Bangladesh Project. DIMEMSEA - 2000. Diabetes in Middle East, Eastern Mediterranean and South East Asia Second Conference 2000, Dhaka, Bangladesh; p38.

4. Ballard DJ, Humphrey LL, Melton LJ, Fronhnert PP, Chu PC, O Fallon WM. Epidemiology of persistent proteinuria in type 2 diabetes mellitus : Population based study in Rochester, Miinnesota; Diabetes 1988; 37: 405-12.
5. USRDS (United States Renal Data Survey) 1993, Bethesda NIH Publication

6. Rahman M, Roy AC, Chowdhury D, Hossain M, Clinicopathological spectrum of renal disease in IPGMR. An analysis of 200 case in 11 years JBCPS 1985; 11: 3-11.

7. Mogensen CE. Christiansen JS. Predicting diabetic nephropathy in insulin-dependent patients. N Engl. J Med 1984;311: 89-93.

8. Mogensen CE. Early glomerular hyperfiltration rate in type 1 diabetes and late nephropathy. Scand J Clin Lab Invest 1986; 46: 201-206.

9. Hasslacher C, Ritz E, Wahl P, Michael C. Similar risks of nephropathy in patients with type 1 or type 2 diabetes mellitus. Nephrol Dial Transplant 1989;4:859 - 63.

10. Myers BD. Progression of overt nephropathy in non insulin dependent diabetes.

Kidney Int 1995; 47: 1781-89.

11. Krolewski A S, Canessa M, Warrm JH, Laffel LMB, Christlieb AR, Knowler WC et al. Predisposition to hypertension and susceptibility to renal disease in insulin dependent diabetes mellitus. N Engl J Med 1988; $318: 140-45$.

12. Seaquist ER. Goetz FC. Rich S. Barbosa J. Familial Clustering Diabetic Kidney disease: Evidence of genetic susceptibility to diabetic nephropathy. N Engl J Med 1989; 320: 1161-65.

13. Pettit DJ, Saad MF, Bennett PH, Nelson RG, Knowler WC, Familial predisposition to renal disease two generations of Pima Indians with type 2 (non insulin dependent) diabetes mellitus. Diabetologia 1990; 33: 438-43.

14. Iqbal M. Sodium- lithium counter transport activity in type 2 diabetic nephropathy.[MD thesis] Dhaka University, 2000.

15. Islam S. Microalbuminuria in under 30 years diabetic subjects. [MD thesis] Dhaka University, 1993.

16. Alam R. Microalbuminuria in under 30 years diabetic subjects.[MD thesis] Dhaka University, 1995.

17. Hada R. Sodium- lithium counter transport activity in RBCs of young diabetics of Bangladesh [MD thesis] Dhaka University, 1998.

18. Mogensen CE, Blood pressure elevation versus abnormal albuminuria in the genesis and production of renal disease in diabetes. Diabetes Care 1992;15: 1192-1204.

19. Wiseman M, Viberti GC, Mackintosh D, Jarrett RJ, Keen H, Glycaemia, arterial pressure and microalbuminuria in type 1 diabetes mellitus.Diabetologia 1984;26: 401-405.

20. Mathiesen DR, Ronn B, Jesen T, Storm B, Deckert T. Relationship between blood pressure and urinary albumin excretion in development of microalbuminuria. Diabetes 1990; 39: 245-49.

21. Schmitz A, Vaeth M, Mogensen CE, Systolic blood pressure related to the rate of progression of albuminuria in NIDDM. Diabetologia 1994;37: 1251-58.

22. Mogensen CE. Systemic blood pressure in glomerular leakage with particular reference to diabetes and hypertension. J Int Med 1994; 235: $297-16$

23. Hansen $\mathrm{KW}$, Christiansen $\mathrm{CK}$, Andersen PH, Pedersen MM, Christiansen JS, Mogensen CE. Ambulatory blood pressure in microalbuminuric type 1 diabetic patients. Kidney International 1992b;41: 847-54

24. Viberti GC, Keen H, Wiseman MJ, Raised arterial pressure in parents of proteinuric insulin dependent diabetics. $\mathrm{Br}$ Med $\mathrm{J}$ 1987;295: 515-18. 
25. Krolewski AS, Doria A, Magre J, Warram JH, Houseman D. Molecular genetic approaches to the identification of genes involved in the development of nephropathy in insulin dependent diabetes mellitus. J Am Soc Nephrol 1992; 3 (Suppl 4): S9-S17.

26. Alberti KGMM, Zimmet Pz. Definition, diagnosis and classification of diabetes mellitus and its complications. In diagnosis and classification of diabetes mellitus provisional report of a WHO Consultation : part 1. Diabetic Med 1998; 157: 539-53.

27. Patric AW, Leslie PJ, Clark BF, Frier BM. The natural history and complications of the microalbuminuric in type 2 diabetes during the first year after diagnosis. Diabetic Med 1990; 7:902-908.

28. Olivarius N, Andreasen AH, Keiding N, Mogensen CE. Epidemiology of renal involvement in newly diagnosed middle aged and elderly diabetic patients : Cross sectional data from the population based study Diabetes care in general practice, Denmark. Diabetologia 1993; 36: 1007-16.
29. Alzaid AA. Microalbuminuria in patients with NIDDM: an overview. Diabetes care 1996; $19: 79-89$.

30. Parving HH, Smidt UM, Friisberg B, Bonne vie-Nielsen V, Andersen AR. A prospective study of glomerular filtration rate and arterial blood pressure in type 1 diabetes with diabetic nephropathy. Diabetologia 1981; $20: 457-61$.

31. Borch-Johnsen K, Andersen PK, Deckert T. The effect of proteinuria on relative mortality in type 1 Diabetes mellitus. Diabetologia $1985 ; 28: 590$ - 96 .

32. Iftekher H. Assessment of renal tubular dysfunction in diabetic nephropathy in type 2 diabetes. MD thesis. Dhaka University, 2001. 